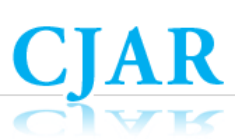

Canadian Journal of Action Research

Volume 19, Issue 2, 2018, pages 48-66

\title{
"It is just too fun to explain": \\ A QUALITATIVE ANALYSIS OF THE RECESS PROJECT IN SEVEN LOWER-SOCIOECONOMIC ELEMENTARY SCHOOLS
}

\author{
Lauren McNamara \\ Ryerson University \\ Meaghan Walker \\ University of Toronto
}

\begin{abstract}
This qualitative report is part of a larger action research study on a topic that is often overlooked in school improvement efforts: Recess and its influence on children's social interactions and developmental trajectories. We introduced The Recess Project into seven lower-socioeconomic elementary schools in southern Ontario. Our intention for this report was to assess how things were progressing in these schools. We describe the strategies we used and the rationale behind the design of the Recess Project and highlight the dynamics between the setting, the children's patterns of interactions, and the potential developmental outcomes. Participants included students, administrators, teachers, university researchers, and university students. Five themes emerged from our analysis: 1) noticeably less discipline issues, 2) more collaborative play and friendships, 3) noticeably more inclusive behaviors, 4) more refined and prosocial interactions overall, and 5) the children were clearly enjoying themselves. We discuss the potential implications of these findings on children's overall wellbeing and school engagement.
\end{abstract}

\section{BACKGROUND}

Some of the most influential experiences for children include social experiences, which are crucial to a child's development, both emotionally and academically (Corkum, Corbin, \& Pike, 2010; Durlack, Weissberg, Dymnicki, Taylor, \& Schellinger, 2011; World Health 
Organization, 1997). Furthermore, contemporary research in the field of social neuroscience can now describe, in extraordinary details, the physiological pathways between the quality of social experiences and long-term health trajectories - highlighting the cumulative and cascading influences of childhood that shape positive or negative outcomes on mental health, health behavior, physical health, and mortality risk (Umberson \& Karas-Montez, 2010).

Often overlooked in school improvement efforts - and unsupported - recess has long been a very important social space for children (Doll, Murphy, \& Song, 2003; McNamara, 2013; McNamara, Lodewyk, \& Franklin, 2018a; McNamara, Lakman, Spadafora, Lodewyk, \& Walker, 2018b; McNamara, Colley, \& Franklin, 2015; McNamara, Vantaaja, Dunseith, \& Franklin, 2014;). Recess in Canada, the United Kingdom, and the United States is generally understood as a break from instruction for children to rest, interact with peers, and engage in physically active play - free from classroom rules and routines (Blatchford \& Baines, 2006; Dessing, Pierik, Sterkenburg, van Dommelen, Maas, \& de Vries, 2013; McNamara et al., 2014; Pellegrini \& Smith, 2005).

The overall benefits of recess are thought to contribute to overall health and well-being by reducing stress, stimulating neurological activity, increasing energy, and fostering social and emotional competencies such as problem-solving, emotional regulation, and coping strategies - all of which are predictive school engagement and academic success (Bagwell \& Schmidt, 2011; Barros, Silver, \& Stein, 2009; Blum, 2005; Durlak et al., 2011; Ramstetter, Murray, \& Garner, 2010).

However, an important question is whether these benefits are being realized. Because recess is a space that is routinely overlooked in school improvement efforts - and consequently remains under-resourced - the result is countless barriers and challenges that not only undermine children's ability to engage positively with peers but also compromises their overall well-being and health trajectories (McNamara et al., 2015).

What's getting in the way? Barriers to healthy, meaningful play during recess. Research on the context of recess has revealed the conventional organizational and logistical factors that negatively shape the social climate. In many school boards, recess is not just a break for children; it is also a break for teachers. Principals are confined by union contracts as to how much time they can require their staff to be outside supporting recess, and the result is a vastly different ratio of adults to children than that in the classroom. It is not unusual to see 1 supervisor to anywhere from 50-200 students on the playground, including kindergarteners (Stanley, Boshoff \& Dollman, 2012; Dubroc, 2007; Jarrett \& Waite-Stupiansky, 2009; McNamara, 2013; McNamara et al., 2014; Pytel, 2009; Robert Wood Johnson Foundation, 2010).

Consequently, minimal supervision constrains equipment availability - as concerns about safety, liability, and theft arise. Limited equipment sets the stage for boredom and conflict and when combined with different ages, play preferences, social skills, and developmental needs, discipline becomes a big challenge and reactive supervision ensues and strict rules 
such as No Running, No Tag, No Cartwheels are put in place. Strict rules likely further impede children's opportunities to connect and engage in developmentally necessary physically active play (see Brussoni et al., 2015 for research on risky play) potentially catalyzing tension, anxiety, uncertainty, social conflict, and negative patterns of interactions among children (McNamara et al., 2018a; McNamara et al., 2015).

Moreover, experiences such as bullying, victimization, and, exclusion not only go unnoticed but are seemingly routine and normalized patterns of behavior on the playground. Current research documents unacceptably high levels of social conflict, victimization, negative affect, and fear (Craig \& Peplar, 1997; McNamara et al., 2018a; McNamara et al., 2015, McNamara et al., 2014; McNamara, 2013; Robert Wood Johnson Foundation, 2010; Vallaincourt et al., 2010; Zumbrunn, Doll, Dooley, LeClair, \& Wimmer, 2013).

Ongoing conflict and experiences such as bullying and exclusion not only undermine children's ability to connect with peers, but they foster feelings of inadequacy, loneliness, and self-doubt that are known precursors of mental illness (Bagwell \& Schmidt, 2011; Eisenberger \& Cole, 2012; Leary \& Baumeister, 2000). From the lens of social neuroscience then, these normalized patterns of maladaptive interactions should be very concerning, particularly in light of the rise in psychopathology in children and adolescents (Canadian Mental Health Association, 2013; Centre for Addiction and Mental Health, 2012; Merikangas, He, Burstein, Swanson, Avenevoli, Cui et al., 2010).

\section{THE RECESS PROJECT}

The Recess Project was developed to address these challenges. Overall, the project is an action research design whereby research is conducted for the purpose of enabling action (see Baum, Macdougall, \& Smith, 2006). It is an iterative approach to research and practice, and the overarching goal of the research team is to improve the way recess is experienced by elementary school students.

Many recess interventions focus on increasing physically active play. The Recess Project takes a slightly different approach, choosing instead to focus first on revising the social climate to foster positive interactions and friendships, as physically active play is more likely to happen in the context of a friendship (Bagwell \& Schmidt, 2011). This approach draws on research from a variety of disciplines, including psychology, sociology, social neuroscience, and anthropology (for a few examples) in an attempt to spark ideas for new practices while also addressing the aforementioned challenges above, namely the lack of supervision, boredom, and social conflict. Over the last 8 years the program has been piloted and revised in in over 30 elementary schools in southern Ontario, Canada.

Design Rationale. Broadly speaking, our research team has learned that a welldesigned recess is one that provides students with a psychologically safe space to engage in a wide variety of play opportunities that are personally meaningful and developmentally appropriate (Centers for Disease Control and Prevention, 2010; Doll, et al., 2003; Durlak et al., 2011; Hyndman, 2016; Massey, Stellino, Mullen, Claassen, \& Wilkison, 2018; McNamara 
et al., 2018a; McNamara et al., 2015; Pellegrini \& Bohn, 2005; Pellegrini et al., 2004; Sibley \& Etnier, 2003). It is one that is well-equipped and fully accessible for all kinds of recreation and play. It includes supportive, adequate, attentive, knowledgeable, accessible, and engaging supervision. It includes an abundance of positive role models. And it includes a social climate that is thoughtfully shaped to encourage inclusive behaviors. The specific design and rationale behind the Recess Project program is listed below (see McNamara, 2013 and McNamara et al., 2014 for further descriptive details of the design).

Designated Staff Member: Recess Coordinator. This role is essential to success and sustainability. Generally, teachers and administrators do not have the necessary time and expertise to commit to the level of detail needed to ensure sustainable changes. As well, volunteers (parents, teachers, university students) cannot provide the commitment and consistency that is necessary for ongoing support (McNamara et al., 2014). Eventually, the role of Recess Coordinator must become part of the internal fabric of the school boards, but for now outsourcing is necessary.

Currently, the Recess Project hires, trains, and places university students in elementary schools to act as the Recess Coordinator, best described as a 'master-planner' for recess. They are well trained to support schools as they integrate recess into widespread school improvement efforts. They work with the staff to map out the playground, manage equipment, and organize games and activities for the younger students to participate in. The coordinators in our project were hired for approximately eight hours weekly for the duration of the entire school year. This continuity was necessary to establish a presence in the school that became familiar and routine as well as have time for planning and preparation. We hired university students enrolled, generally, from programs such as Education, Kinesiology, Sport Management, and Child and Youth Studies.

This is a proactive role, rather than reactive. It allows someone designated time to recess time to plan and design based on the unique circumstances of the school. They work closely with children to learn their needs and the activities and supports they are interested in and then work collectively to deliver in such a way as to create new routines, norms, rules, attitudes, and expectations that are understood by everyone in the school. For the children at play, the new routines are critical to reduce the uncertainty, ambiguity, and anxiety about what to expect, what to do, and how to interact - providing a foundation for an overall culture change (Wenger, 1998).

Moreover, they work collectively with staff to attend explicitly to children from vulnerable populations: children with disabilities or impairments, children of new immigrants, children with social limitations. Research indicates that typically marginalized groups experience more victimization and negative affect during recess and need more support (McNamara et al., 2018b; and broadly, Keating \& Hertzman, 1999).

Options: A continuum of activities. Recess is typically composed of mixed ages, different temperaments, various social skills, and personal circumstances resulting in diverse developmental needs and interests of the children (Doll, 2003; McNamara et al., 
2018a; McNamara et al., 2018b; McNamara et al., 2015; McNamara et al., 2014; McNamara, 2013;). Providing a range of options gives them opportunities to rest or connect with likeminded peers while boosting engagement, enjoyment, and physical activity and reducing conflict and victimization (McNamara et al., 2014; Stellino, Sinclair, Partridge, McClary King, 2009; Verstaete, Cardon, DeClercq, DeBourdeau-dhuij, 2006; Pellegrini et al., 2005a).

Ultimately, this time allows for unstructured play, which we refer to as a spontaneous play free from the direction of adults but protected from the effects of bullying and social harm (see McNamara et al., 2015; Ramstetter, Murray, \& Garner, 2010; Barros et al., 2009; Burdette \& Whitaker, 2005).

We offer a rotating schedule of activity areas or "zones" - such as a Frisbee zone, skipping zone, soccer zone, games, areas for unstructured creative play, active game play, quiet areas, and so on. We also explore occasional alternatives to outdoor recess (Zumba, yoga classes in the gym, craft and skipping clubs) run by a university volunteer or community partner/YMCA. Non-physical options such as craft clubs, chalking areas, book and music clubs can encourage friendships and reduce stress (McNamara et al., 2014).

Leadership opportunities: Junior Recess Leaders. A fundamental part of the Recess Coordinator position is to recruit, train, schedule, and supervise rotating cohorts of older students from grades 5-8 that volunteer as Junior Recess Leaders (JRLs). The presence of cohorts of JRLs provides additional protective support for the primary children. They are intentionally trained to teach and model prosocial skills during recess and provide support to younger peers as the initiate play, build friendships, negotiate social groups, and work through conflict - a model that aligns with Vygotsky's (1978) Zone of Proximal Development. JRLs, usually in pairs, are assigned to a "zone" (e.g. skipping zone, Frisbee zone) whereby they are responsible for supporting the children and monitoring the corresponding equipment.

We have learned that these JRLs are important levers for change and must be carefully attended to in order for change to be sustainable. We ask JRLs to commit to two recesses per week for a 10-week rotation. The continuity allows them to become familiar role models while the limited shifts prevent burnout, keep interest high, and ensure that they have time to enjoy their own recess (McNamara et al., 2014). As well, we encourage them to engage in regular debriefing sessions with the Recess Coordinator.

In previous research (McNamara et al., 2018a; McNamara et al., 2014; McNamara, 2013) we found that these ongoing regular interactions between older and younger students encourage positive connections. The continuity provides opportunity for the JRLs to observe and learn more about the relations and dynamics among the primary children, allowing them to make decisions about how best to support them. We see much of this with the help of social cognitive theory (e.g. Vygotsky, 1978; Bandura, 1986), as the younger children spontaneously copy the behaviors of their older peers and start to become kinder, nicer, and more inclusive. These behaviors, when sustained and supported, will likely 
contribute to a cultural shift in social patterns, expectations, beliefs, and attitudes that shape the social climate of recess (e.g. Hargreaves, Lieberman, Fullan, \& Hopkins, 2014).

\section{Study Design and Population}

Action research is aligned with the assumptions of cultural-historical activity theory, a conceptual framework first initiated by Vygotsky (1978) and later expanded by Leont'ev (1978) and Engeström (1987/2015). Cultural historical activity theory assumes that the behavior of individuals is dynamically entwined in their social and cultural contexts. It provides a conceptual lens from which to analyze the complexity of human behavior - the rules, intentions, routines, patterns, and other mediating influences that shape the individual, their relationships, and the contexts in which they are situated.

We adopted an inductive, exploratory approach that includes data from questionnaires, interviews, and field notes. Both the interviews and the questionnaires included openended, semi-structured questions. The questions were designed to allow participants to articulate opinions, beliefs, perspectives, experiences, descriptions, contrasts, needs, interests, wishes, challenges, and concerns about the influence of the Recess Project. This triangulation technique is used in qualitative research to enhance the trustworthiness and validity of the findings (Miles, Huberman, \& Saldana, 2013).

The data for this report were collected from across seven elementary schools in four southern Ontario, Canada school districts. Enrollments range from 150 to 400 and include kindergarten through grade eight students. Data were gathered via semi-structured interviews and the same interview questions were used across participants. We interviewed principals $(\mathrm{N}=7)$, students $(\mathrm{N}=28$, grades four to eight), teachers $(\mathrm{N}=5)$, and Recess Coordinators (4). The interview guide was informed by the study aim, existing literature, and the team's expertise in the area of social inclusion and recess. Data were analyzed using a descriptive thematic analysis approach (Lopez \& Willis, 2004). Braun and Clark's (2006) guidelines for thematic analysis were followed whereby codes were created and major themes were sourced.

The seven schools involved in this study are new additions to our ongoing action research collaboration. These schools were selected based on their neighborhood demographic information, specifically schools from low socioeconomic neighborhoods. Research indicates that students from lower SES populations are disproportionally challenged by multiple risk factors that negatively influence their overall developmental health and academic success, which then starts a feedback loop as poor academic progress further perpetuates their low SES as well as the SES status of the community (Keating \& Hertzman, 1999). Our project is designed to provide supports that mitigate many of the risk factors that make students from low SES populations vulnerable during socialization and play (see Umberson \& Karas-Montez, 2011; Gallo \& Matthews, 2003; Barros et al., 2009. Selecting these particular schools is a type of intentional sampling that is used in qualitative research in order to understand better the perceptions of those closest to the problem (Creswell, 2007; Mays \& Pope, 1995). 


\section{Results}

Our intention was to explore the progression of the Recess Project in seven schools that newly implemented our program over the 2017-2018 school year. We wanted to address the challenges revealed in previous research on recess, and moreover, we wanted to analyze if the patterns of interaction among children were changing in the direction intended. As well, we wanted to bring the students' voices to the foreground and then complement their voices with the perspectives of the staff.

Five key themes emerged from our analysis of the data, and these themes were similar to our previous research reports (McNamara et al., 2014; McNamara, 2013). The first is there were noticeably less discipline issues. The second is the students were more engaged in collaborative play and actively building new friendships. The third is the students were exhibiting more inclusive behaviors among each other. The fourth is the children were showing more refined and prosocial interactions. And finally, the children were enjoying recess more.

The five themes were difficult to delineate as each is tightly entwined with the others in dynamic ways, but the overarching result is clear: the patterns of interaction are changing favorably. The themes underscore the importance of recess as a social space, first and foremost. They reflect a desire and need for social connectedness and emphasize the benefits of a safe and accepting social climate. The exemplars below highlight the ways in which schools can manipulate the routines and, in turn, the setting to foster more positive patterns of interaction, and in time, reshape the overall culture of recess.

Theme 1 - Less discipline issues: "I really liked that older students were helping others, they were engaged, they loved the activities, and the number of recess incidents decreased."

The rationale behind the design of the Recess Project, as discussed earlier, is to fundamentally alter the way children interact in this setting. When children are happy, engaged, and interacting comfortably there is a very noticeable difference in the number of discipline issues that arise. It is a preventive approach and, in our work, this is typically the most noticeable (and welcome) impact for principals.

- "Fewer issues during outdoor play. Students were not bored outsides and always had many options to choose from." (Teacher)

- "Helped alleviate some discipline issues." (Teacher)

- "Less behavioural issues." (Principal)

- "Less arguments..." (Principal)

Principals attribute the success to the Recess Coordinator position, as there is now someone with designated time to plan and manage recess effectively. Furthermore, they underscore the principals underscored the need to have a designated person to ensure the JRLs were well trained and supervised. 
- "I am confined by Union contracts as to how much time I can ask people to be outside supporting recess." (Principal)

- "The biggest thing for me is to build the capacity in student leaders and have them continue to be leaders in the playground to help students. It can't just be an 8 week project that ends, and all the gains stop. It needs to be supported and sustained in the school yard to ensure that it continues. I really liked that older students were helping other, they were engaged, they loved the activities, and the number of recess incidents decreased." (Principal)

Theme 2 - Students were more engaged in collaborative play and actively building new friendships: "I have made a lot of friends."

Both students and staff reported that prior to the Recess Project, recess was boring and as a result the social climate was difficult for students to navigate:

- "Students go outside and don't know exactly what to do." (Principal)

- "There are students who may not know how to engage in proper recess activities, and/or have the skill to do so." (Principal)

- "Student conflicts while at recess. Students do not have the capacity as yet to resolve problems." (Principal)

- "Our kids lack some social skills so they are unable to deal with certain feelings in positive ways. They will hit rather than talk or go and see an adult." (Principal)

- "ASD kids were often playing alone, often isolated." (Principal)

- "Social/Communication disabilities are common and these students often experience bullying or exclusion." (Principal)

- "Students do not know how to manage conflicts. Socially awkward students are often vulnerable." (Principal)

The study participants reported that the injection of new activities engaged a wide variety of the students and effectively catalyzed collaborative play among them:

- "Recess was boring before and now it isn't because of all the activities going on." (Student)

- "I see a lot more kids doing something at recess and they aren't bored." (Student)

- "It actually made kids want to go play and gave them something to look forward to." (Student)

- "This project encouraged participation and also allowed them to play with students they normally wouldn't play with." (Teacher)

- "There were more things to do so if your friend wasn't there you could go play with a different group of people." (Student)

- "It allowed all students to participate in the various activities provided as well as provide leadership opportunities for those interested." (Principal) 
The participants reported that the influx of activities and guidance from JRLs provided the scaffolding that the students needed to make new friendships. The students expressed that it was easier to make more friends and they enjoyed having opportunities to engage with students in different grades.

- "People play with each other." (Student)

- "It made a big difference because kids got along with some of their enemies and they turned their enemies into their friends." (Student)

- "Friends between grades, meeting new students, grades 1-6 students talking to each other." (Principal)

- "We got to play with the little kids and usually we don't get to. We also got to meet new people and play with them." (Student)

- "[The Recess Project] allows students to work with students they may not normally associate with." (Teacher)

- "[My favourite part is] seeing every child being involved." (University Coordinator)

Theme 3 - The students were exhibiting more inclusive behaviors among each other: "I got to experience talking to people and playing with people I don't really talk to."

The participants reported that, prior to implementation of the Project, they were disturbed by social behaviors that excluded some children from engaging in play.

- "One thing I dislike is that other people sometimes get disincluded and get bullied." (Student)

- "I don't like when people get mad when other people are excluded or say you can join but you can't." (Student)

- "I don't like all of the fighting that goes on." (Student)

- "There are students who are constantly excluded or picked on that do not feel safe at recess." (Principal)

Students and staff reported that the ongoing presence of the JRLs appeared to promote inclusive behaviors, which in turn, influenced the way the younger children interacted with each other. Principals and teachers indicated that they were pleased, and surprised, to see the older students being leaders and role models. But more importantly, the students themselves noticed the change.

- "I think it made a difference because for those kids feeling left out they couldn't be excluded from this because everyone was allowed to join and was allowed to play whatever they wanted." (Student)

- "The leaders are more of a good influence on the younger kids so it is even better for them." (Student)

- "I like it because I get to play with kids and make them happy. Especially the ones that are down because you can make them happy by including them." (Student)

- "It was fun because I got to help out with it. It was fun to see how other people enjoyed it. I liked getting to help with the kids and make them smile." (Student) 
- "If we don't have any friends that won't let us join with have someone to play with now because of this." (Student)

- "Well more kids weren't left out. The older kids that didn't have anyone to hang out with go to help and play with kids." (Student)

Theme 4: More refined social interactions. "I believe it taught students social skills and cooperation skills.”

Principals and staff initially reported that their greatest challenge with recess was the gap in social development among students.

- "While many may have coping skills to solve disputes and regulate behaviour, many do not." (Principal)

- "There are some students that find it difficult asking others to play at recess." (Teacher)

Participants indicated that the Recess Project had quickly transformed the recess environment into a fun and enjoyable setting for all students to engage in. More so, the principals and teachers recognize that the participation and engagement - along with the guided scaffolding and role models - has led to the development of more advanced and refined social skills for students, such as effective problem solving, altruism, and cooperation.

- "Students acquired new skills socially and physically." (Teacher)

- "I believe it taught students social skills and cooperation skills." (Principal)

- "I think it made a difference because kids get to interact with each other and learned how to share and be fair." (Student)

- "It helped some students socially, as they developed relationships with other students they normally wouldn't play with." (Teacher)

- "We had far fewer conflicts between students, less students claimed to be bored at recess, students acquired new skills socially and physically. They were more engaged." (Teacher)

Theme 5: More Enjoyment: "Everyone is having fun all of the time. It is just too fun to explain."

Enjoyment is often a good indicator that things are going well. Time and again we witnessed the children just appearing happy. We so often overlook enjoyment and laughter at school, yet it has a range of physiological effects on overall physical and mental health and, importantly, is an important mediator of human connection (see Savage, Lujan, Thipparthi, \& DiCarlo, 2017). Students discussed that prior to the Recess Project recess could be a boring, unstructured time. Initially students reported a lack of opportunities to engage in and few fun and enjoyable activities.

- "I hated it. I did nothing." 
When asked about the impact of the Recess Project, they referenced the fun, laughter, and joy that they were experiencing:

- "It has been fun. I had so much laughs." (Student)

- "I love seeing how happy the students are when they see us." (Recess Coordinator)

- "It is really fun." (Student)

- "It was fun to see how other people enjoyed it. I liked getting to help with the kids and make them smile." (Student)

And our personal favourite:

- "The recess project. It changed my life." (Student)

\section{Discussion}

It is generally understood (by adults) that children need recess for a number of reasons. They need a break from the structured classroom activities and focused attention, they need to relieve the pent up academic stress, and they need to re-energize themselves in order to return to class refreshed and ready to focus again. However, our ongoing research with children has found that recess, for the children, has a very different purpose. To them, it is a critically important social space that provides an opportunity to connect with their peers. Research shows that the need for interpersonal closeness grows more important and more complicated - as children enter elementary school (see Bagwell \& Schmidt, 2011, for a review). Recess is typically the only time in the school day for children to interact freely with their peers. It is, based on their accounts, the part of the school day, free from classroom constraints, to allow the students to connect through play, interaction, and socialization. This is an important thing to recognize. The need to foster and maintain social connections - the need to belong - is a fundamental motivation that drives human behavior (DeWall \& Bushman, 2011; Baumeister \& Leary, 1995).

Yet, as we discussed earlier, the benefits of recess - a break, a need burn off energy, to recharge, as well as a need to connect - appear to be compromised due to the antiquated routines of schools. Moreover, many children may not even realize these benefits. In our analysis, we brought the voices of children and substantiated them with the voices of school staff. We viewed these insights from multiple theoretical and conceptual lenses in order to better understand how the Recess Project can provide the supports necessary for children to enjoy a recess that meets their continuum of needs.

The Recess Project was implemented in these seven schools for the duration of only one school year - in some schools we even started later than the start date of September - yet it was evident that the project does more than simply address common dilemmas at recess, it shifts and improves the way the children interact with each other. In other words, it shifts the social climate and reshapes the culture of recess. It shifted the culture from one that was characterized by exclusion, rejection, and boredom to one that fostered inclusion, engagement, enjoyment, and friendships. 
Why is this important? Children are in school for a majority of their childhoods and thus this setting is a critical mediator of early social behaviors that set the foundation for later outcomes (Stewart, Sun, Patterson, Lemerle, \& Hardie, 2004). Early social behaviors are predictive of later measures of mental health, stability, and life satisfaction (Umberson \& Karas-Montez, 2010). The daily cumulative impact of recess experiences on children's mental health may be significant, particularly for children who are constantly rejected, isolated, or victimized due to limited or ineffective social skills (see McNamara et al., 2018b).

Our analysis revealed that there were noticeably less discipline issues. It is clear, both from our analysis and from current research, that many children need to learn how to establish positive and meaningful friendships and how do negotiate conflict effectively. This is particularly important for children in low income neighborhoods, as low socioeconomic status is predictive of social competence (see Hosokawa \& Katsura, 2017). These need positive role models and they need supportive scaffolding as they learn to navigate friendships. In our project, children were provided with an array of possibilities designed to help them interact more effectively with their peers. Moreover, they were provided with activities and spaces that were based on what they requested, what they were interested in. Our rationale is that this kind of semi-structure provides them the necessary scaffolding to establish positive, reciprocal, and cooperative interactions. Not surprisingly, the participants indicated that when the children were engaged in these activities they were generally happy and content - the result is that the students were less likely to engage in problem behavior and conflict.

Our analysis also revealed that the students were more engaged in collaborative play and actively building new friendships. Again, by providing them with the support and scaffolding these activities can bridge relationships between children with similar interests; the activities and scaffolding act as levers to catalyze interactions with other children that they may not otherwise have the opportunity or ability to do so (see Yonezawa, Jones, \& Joselowsky, 2009; Wenger, 1998). These scaffolded, supported activities can help them initiate a social bond that can continue to be built upon through further play experiences - providing a safe setting that can pave the way for feelings of connection and belonging.

Not surprisingly, then, the results indicated that the students were exhibiting more inclusive behaviors among each other. There is a wide range of differences among students on a typical school playground. As mentioned earlier, research suggests that when these differences go unsupported, it tends to challenge students' capacity to negotiate play effectively. Maladaptive patterns of interactions can then take hold, and the result, as we have seen, is dysfunctional patterns of social interactions that can lead to isolation, exclusion, victimization, and loneliness. One of the key roles of the JRLs is to model inclusive behaviors. They are intentionally taught to use words, phrases, and actions that reflect compassion and inclusion. They seek out children who appear lonely or marginalized, and they invite them into the activity. The primary students, we witness time and again, spontaneously copy these behaviors. These observations are not surprising in 
that they align with well-established research on peer interactions. As children engage with each other they learn fundamental social cues, rules, and routines (Hosokawa \& Katsura, 2017).

Likewise, the children were showing more refined and prosocial interactions overall. More advanced social competencies such as conflict resolution, perspective-taking, empathy, reciprocity, and emotional regulation develop in the context of positive social relationships. In other words, children need supportive friendships in order to refine their social competencies (Bagwell \& Schmidt, 2011). Importantly, and the ultimate goal of our project, is that children begin to internalize these social skills as they develop, allowing them regulate their thoughts and behaviors more effectively in future interactions, further shaping their developmental trajectories (Umberson \& Karas-Montez, 2010; Bear \& Watkins, 2006)

And finally, the children were enjoying recess more. One of the benefits of social relationships is sharing joy and excitement. In the context of our implementation, enjoyment, contentment, and happiness indicative that positive relationships are being established, as research shows a connection between positive emotionality and positive social relationships (e.g. Denham, Bassett, \& Wyatt, 2007). From a well-being and health perspective, these affective responses not only trigger physiological responses that have a buffering affect on stress, but they help foster the larger sense of meaning, purpose, and engagement in life (see Cohen, 2004) - of which the academic benefits are clear - healthy children are better learners (WHO, 1997).

These findings mirror the themes in our previous research: children need well-supported opportunities to connect. The activities and organization that we offer help to mediate relationships, engagement, and physically active play. The JRLs provide encouragement and scaffolding and provide opportunities for the leaders themselves to develop and refine their social skills. Moreover, not only do the JRLs provide increased 'supervision', they offer a consistent presence and ongoing support. The younger children look to them to make sense of the social context, to help organize the activities and zones, and to help them when they need help with conflict resolution. The younger children do not yet have the ability to connect effectively with their peers. If these children do not have the capacity to connect, they will have trouble cultivating and maintaining connections. Therefore, the scaffolding has a very important implication - if the support and scaffolding continue, then the younger children's experiences will likely influence their development of social and emotional competencies that allow them to build a foundation for social adjustment in later years.

But what must be underscored, again, is that the JRLs themselves need to be supported and that is provided by the role of a Recess Coordinator. 


\section{CONCLUSION}

Current research on recess provides the necessary rationale as to why recess is developmentally important and needed: this time in the school day is said to have physical, academic, social, and emotional influences. However, these effects, depending on whether they are positive or negative, can contribute either to cumulative advantage or cumulative disadvantage. Our research highlights the importance of reshaping the conventional organization of recess in order to promote the likelihood of cumulative advantage.

Our research design introduces an important new role in the organization of a school: that of Recess Coordinator. The rationale for the specific training of this 'master planner' is drawn from our ongoing action research collaboration as well as a variety of other empirical research and theories - with the goal of enacting cultural change on the playground. The change we are after is to create new and positive patterns of interactions among the children, patterns that are inclusive, compassionate, accepting, and kind. The rationale is that these interactions will shape their thinking, behavior, and interactions that will follow them into adulthood, dynamically influencing their future trajectories.

Recess has been a long overlooked space that has a clear influence on children's lives. If we are serious about enacting change, we must find ways to align the Education Acts, provincial and territorial policies, collective agreements, and funding opportunities to bring care, compassion, and civility to our Canadian school playgrounds.

\section{REFERENCES}

Bagwell, C. L., \& Schmidt, M. E. (2011). Friendships in childhood and adolescence. New York, NY: Guilford Press.

Bandura, A., \& National Institute of Mental Health. (1986). Prentice-Hall series in social learning theory. Social foundations of thought and action: A social cognitive theory. Englewood Cliffs, NJ:Prentice-Hall, Inc.

Barros, R. M., Silver, E. J., \& Stein, R. E. K. (2009). School recess and group classroom behavior. Pediatrics, 123(2), 431-436.

Baum, F., Macdougall, C., \& Smith, D. (2006). Participatory action research. Journal of Epidemiol Community Health, 854-857. https://doi.org/10.1136/jech.2004.028662

Baumeister, R. F., \& Leary, M. R. (1995). The need to belong: Desire of interpersonal attachments as a fundamental human motivation. Psychological Bulletin, 117(3), 497-529.

Bear, G. G., \& Watkins, J. M. (2006). Developing self-discipline. In G. G. Bear \& K. M. Minke (Eds.), Children's needs III: Development, prevention, and intervention (pp. 29-44). Bethesda, MD: National Association of School Psychologists. 
Blatchford, P., \& Baines, E. (2006). A follow up national survey of breaktimes in primary and secondary schools: Reported to Nuffield foundation. Retrieved from http://www.nuffieldfoundation.org

Blum, R. (2005). School Connectedness: Improving the lives of students. Johns Hopkins Bloomberg School of Public Health, Baltimore, Maryland. Retrieved from http://cecp.air.org/download/MCMonographFINAL.pdf

Braun, V., \& Clarke, V. (2006). Using thematic analysis in psychology. Qualitative Research in Psychology, 3(May 2015), 77-101. https://doi.org/10.1191/1478088706qp063oa

Brussoni, M., Gibbons, R., Gray, C., Ishikawa, T., Sandseter, E. B. H., Bienenstock, A., ... Tremblay, M. (2015). What is the relationship between risky outdoor play and health in children? A systematic review. International Journal of Environmental Research in Public Health, 12, 6423-6454.

Burdette, H. L., \& Whitaker, R. C. (2005). Resurrecting free play in young children: Looking beyond fitness and fatness to attention, affiliation, and affect. JAMA Pediatrics, 159(1):46-50.

Canadian Mental Health Association (CMHA). (2013). Fast facts about mental illness. Retrieved from http://www.cmha.ca/media/fast-facts-about-mental illness/\#.UzZEllnes s/\#.UzZEu_ldWSo

Centre for Addiction and Mental Health. (2012). Mental illness and addiction statistics. Retrieved from http://www.camh.ca/en/hospital/about_camh/newsroom/for_ reporters/pages/addictionmentalhealthstatistics.aspx

Centers for Disease Control and Prevention. (2010). State Indicator Report on Physical Activity, 2010. Atlanta, GA: U.S. Department of Health and Human Services.

Cohen, S. (2004). Social relationships and health. American Psychologist, 59(8), 676-684.

Corkum, P., Corbin, N., \& Pike, M. (2010). Clinical corner evaluation of a school-based social skills program for children with Attention-Deficit/Hyperactivity Disorder. Family and Behaviour Therapy, (April 2009), 139-151. https://doi.org/10.1080/07317101 003776472

Craig, W., \& Pepler, D. J. (1997). Observations of bullying and victimization in the schoolyard. Canadian Journal of School Psychology, 13, 41-60.

Creswell, J. W. (2007). Qualitative inquiry and research design: Choosing among five traditions (2nd ed). Thousand Oaks, CA: SAGE.

Denham, S. A., Bassett, H. H., \& Wyatt, T. (2007). The socialization of emotional competence. Child Development, 7, 238-256. 
Dessing, D., Pierik, F. H., Sterkenburg R. P., van Dommelen, P., Maas, J., \& de Vries, S. I. (2013). Schoolyard physical activity of 6-11 year old children assessed by GPS and accelerometry. International Journal of Behavioral Nutrition and Physical Activity, 10:97.

DeWall, C. N., \& Bushman, B. J. (2011). Social acceptance and rejection: The sweet and the bitter. Current Directions in Psychological Sciences, 20(4), 256-260.

Doll, B., Murphy, P., \& Song, S. Y. (2003). The relationship between children's self-reported recess problems, and peer acceptance and friendships. Journal of School Psychology, 41(2), 113-130.

Dubroc, A. M. (2007). Is the elimination of recess in school a violation of a child's basic human rights? Retrieved from http://files.eric.ed.gov/fulltext/ED495814.pdf

Durlack, J., Weissberg, R., Dymnicki, A., Taylor, R., \& Schellinger, K. (2011). The impact of enhancing students' social and emotional learning: A meta-analysis of school-based universial interventions. Child Development, 82(1), 4-5-432.

Eisenberger, N. I., \& Cole, S. W. (2012). Social neuroscience and health: Neurophysiological mechanisms linking social ties with physical health. Nature Neuroscience, 15(5), 669-774.

Engeström, Y. (1987/2015). Learning by expanding. An activity-theoretical approach to developmental research. New York: Cambridge University Press.

Gallo, L. C., \& Matthews, K. A. (2003). Understanding the association between socioeconomic status and physical health: Do negative emotions play a role? Psychological Bulletin, 129(1).

Hargreaves, A., Lieberman, A., Fullan, M., \& Hopkins, D. W. (Eds.). (2014). International handbook of educational change: Part two (Vol. 5). Germany, Springer.

Hosokawa, R., \& Katsura, T. (2017). A longitudinal study of socioeconomic status, family processes, and child adjustment from preschool until early elementary school: The role of social competence. Child and Adolescent Psychiatry and Mental Health, 11(62).

Hyndman, B. (2015). Where to next for school playground interventions to encourage active play? An exploration of structured and unstructured school playground strategies. Journal of Occupational Therapy, Schools, \& Early Intervention, 8:1, 56-67, doi: $\underline{10.1080 / 19411243.2015 .1014956}$

Jarrett, O. S., \& Waite-Stupiansky, S. (2009). Recess-It's indispensable! Young Children, 64(5), 66-69. 
Keating, D. P. \& Hertzman, C. (Eds.). (1999). Developmental health and the wealth of nations: Social, biological, and educational dynamics. NY: Guilford Press.

Leary, M. R., \& Baumeister, R. F. (2000). The nature and function of self-esteem: Sociometer theory. In M. P. Zanna (Ed.), Advances in experimental social psychology (Vol. 32, pp. 1-62). San Diego, CA: Academic Press.

Leont'ev, A. N. (1978). Activity, consciousness, and personality. Englewood Cliffs: PrenticeHall.

Lopez, K., \& Willis, D. (2004). Descriptive versus interpretive phenomenology: Their contributions to nursing knowledge. Qualitative Health Research, 14(5), 726-735.

Massey, W. V., Stellino, M. B., Mullen, S. P., Claassen, J., \& Wilkison, M. (2018). Development of the great recess framework - observational tool to measure contextual and behavioral components of elementary school recess. BMC Public Health, 18, 394. http://doi.org/10.1186/s12889-018-5295-y

Mays, N., \& Pope, C. (1995). Qualitative Research: Rigour and Qualitative Research. BMJ, 311:109.

McNamara, L. (2013). What's getting in the way of play? An analysis of the contextual factors that hinder recess in elementary schools. Canadian Journal of Action Research, 14(2), 3-21.

McNamara, L., Colley, P., \& Franklin, N. (2015). School recess, social connectedness and health: A Canadian perspective. Health Promotion International, 1-11. https://doi.org/10.1093/heapro/dav102

McNamara, L., Lodewyk, K., Franklin, N. (2018a). Recess in elementary school: A study of belongingness, affect, and victimization on the playground. Children and Schools, $40(2)$.

McNamara, L., Lakman, Y., Spadafora, N., Lodewyk, K., Walker, M. (2018b). Recess and children with disabilities: A mixed-methods pilot study. Disability and Health Journal, 11(4).

McNamara, L., Vantaaja, E., Dunseith, A., Franklin, N. (2014). Tales from the playground: Transforming the context of recess through participatory action research. International Journal of Play, 4(1).

Merikangas K., He, J., Burstein, M., Swanson, S., Avenevoli, S., Cui, L., ... Swendsen, J. (2010). Lifetime prevalence of mental disorders in US adolescents: Results from the National Comorbidity Study--Adolescent Supplement (NCS-A). doi:10.1016/j.jaac.2010.05 .017. http://europepmc.org/abstract/MED/20855043. 
Miles, M. B., Huberman, A. M., \& Saldana, J. (2013). Qualitative data analysis (3rd ed.). Thousand Oaks, CA: SAGE.

Pellegrini, A. D., \& Smith, P. K. (2005a). Recess: Its role in development and education. Mahwah, NJ: Erlbaum.

Pellegrini, A. D., \& Bohn, C. (2005b). The role of recess in children's cognitive performance and school adjustment. Educational Researcher, 34, 13-19.

Pytel, B. (2009). Pros and cons of recess time in schools: Is recess a mere tradition or a vital piece in education? Retrieved from http://www.isbe.state.il.us/

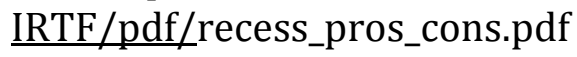

Ramstetter, C. L., Murray, R., \& Garner, A. S. (2010). The crucial role of recess in schools. The Journal of School Health, 80(11), 517-526.

Robert Wood Johnson Foundation. (2010). The state of play: Gallup survey of principals on school recess. Princeton, NJ. Retrieved from www.rjwf.org.

Savage, B. M., Heidi, L., Lujan, H. L., Thipparthi, R. R., \& DiCarlo, S. E. (2017). Humor, laughter, learning, and health! A brief review. Advances in Physiology Education, 41:3, 341-347.

Sibley, B. A., \& Etnier, J. L. (2003). The relationship between physical activity and cognition in children: A meta-analysis. Pediatric Exercise Science, 15, 243 - 256.

Stanley, R. M., Boshoff, K., \& Dollman, J. (2012). Voices in the playground: A qualitative exploration of the barriers and facilitators of lunchtime play. Journal of Science and Medicine, 15(1), 44-51.

Stellino, M. B., Sinclair, C. D., Partridge, J. A., McClary King, K. (2009). Differences in children's recess physical activity: Recess activity of the week intervention. Journal of School Health, 89(9).

Stewart, D. E., Sun, J., Patterson, C., Lemerle, K., \& Hardie, M. W. (2004). Promoting and building resilience in primary school communities: Evidence from a comprehensive 'health promoting school' approach. International Journal of Mental Health Promotion, 6(3), 26-31.

Umberson, D., \& Karas-Montez, J. (2010). Social relationships and health: A flashpoint for health policy. Journal of Health and Social Behavior, 51(Suppl.), S54-S66.

Vaillancourt, T., Brittain, H., Bennett, L., Arnocky, S., McDougall, P., Hymel, S., ... Cunningham, L. (2010). Places to avoid: Population-based study of student reports of unsafe and high bullying areas at school. Canadian Journal of School Psychology, $25,40-54$. 
Verstaete, S. J. M., Cardon, G. M., DeClercq, D. L. R., DeBourdeau-dhuij, I. M. M. (2006). Increasing children's physical activity during recess periods in elementary schools: The effects of providing game equipment. European Journal of Public Health, 16:415419.

Vygotsky, L. (1978). Mind in society: The development of higher psychological processes. Cambridge, MA: Harvard University Press.

World Health Organization. (1997). Promoting health through schools. Report of a WHO Expert Committee on Comprehensive School Health Education and Promotion. WHO Technical Report Series No 870. World Health Organization, Geneva, Switzerland.

Wenger, E. (1998). Communities of practice: Learning, meaning, and identity. Cambridge: Cambridge University Press.

Yonezawa, S., Jones, M., \& Joselowsky, F. (2009). Youth engagement in high schools: Developing a multidimensional, critical approach to improving engagement for all students. Journal of Educational Change, 10, 191-209.

Zumbrunn, S., Doll, B., Dooley, K., LeClair, C., \& Wimmer, C. (2013). Assessing student perceptions of positive and negative social interactions in specific school settings. International Journal of School and Educational Psychology, 1(2), 82- 93.

\section{BIOGRAPHICAL NOTE:}

Dr. Lauren McNamara is the Founder and Director of Recess Project Canada and a Research Associate at Ryerson University's Diversity Institute. Trained in Educational Psychology and Learning Sciences, Dr. McNamara has a research interest in the role of relationships in schools. She works closely with universities, school boards, students, and community partners to mobilize change and ensure relationships and well-being are part of the national conversation of healthy schools. She was awarded a lifetime Fellowship to Ashoka for her work.

Meaghan Walker recently obtained an MS degree from the University of Toronto Rehabilitation Sciences, completing her research at Holland Bloorview Kids Rehabilitation Hospital. 